\title{
Veredas do pertencimento ao Povo do Gerais: roça, religião e mobilização étnica em movimento
}

\section{Chegando ao Gerais Velho}

Os processos de formação e transformação de um campesinato negro no Brasil constituem um rico campo de estudo, cujo interesse tem mobilizado desde historiadores da escravidão e da pós-abolição, até antropólogos envolvidos em pesquisas sobre a identidade quilombola em contextos rurais. $^{2}$ Há alguns anos venho me dedicando a investigar etnograficamente populações negras rurais e ribeirinhas no Vale do Alto Médio São Francisco, no norte de Minas Gerais. Desta posição, busco apresentar uma contribuição ao debate sobre o pertencimento étnico e territorial a partir de um eixo que é significativo para os meus interlocutores: os pequenos e grandes deslocamentos que são constitutivos da vida social de Gerais Velho, uma comunidade ${ }^{3}$ negra rural localizada na região norte de Minas Gerais.

Segundo pesquisa realizada em períodos intermitentes entre 2012 e 2013,4 Gerais Velho é um povoado rural, composto de aproximadamente 70 residências que vivem em pequenos sítios, distante $22 \mathrm{~km}$ da sede municipal de Ubaí e $592 \mathrm{~km}$ de Belo Horizonte. Ubaí foi um antigo distrito de Brasília de Minas e tornou-se município em 1963. Segundo dados do Censo 2010 do IBGE, o município possui 11.681 habitantes, distribuídos em uma área de $820,584 \mathrm{~km}$. Gerais Velho, por sua vez, não chega a constituir um distrito de Ubaí. A comunidade se localiza a $6 \mathrm{~km}$ da estrada estadual MG 202. Segundo alguns moradores mais antigos, o território em que se localiza a comunidade se situava numa área denominada de Fazenda Sabões e Vista Nova, tendo seu nome mudado a

\footnotetext{
${ }^{1}$ Doutorado em Antropologia Social pelo Museu Nacional da Universidade Federal do Rio de Janeiro (MN/UFRJ), professor adjunto IV de Antropologia no Instituto Multidisciplinar da Universidade Federal Rural do Rio de Janeiro (IM/UFRRJ) e membro do grupo de pesquisa Núcleo de Estudos Rurais (NuERs) da Universidade Federal Fluminense (UFF). Email: felipebenites74@gmail.com.

2 Alguns trabalhos como os de Arruti (1997, 2006), Gomes (2006, 2015) e Mello (2012) são exemplos destacados desta literatura.

${ }^{3}$ Uso o termo comunidade em um sentido êmico, tal como é utilizado pelos meus interlocutores.

${ }^{4}$ A pesquisa contou com apoio financeiro da Faperj.
} 
partir de 1981, quando foi fundada a primeira associação comunitária de moradores, com o auxílio da Emater. A comunidade tem como fronteira o território de outras comunidades rurais: Jataí, Coqueiro, Engenho, Malhada Bonita, Serragem, Brejinho, Brejão e Passagem Branca. Como as casas são um tanto distantes umas das outras, as pessoas costumam se deslocar dentro da comunidade de cavalo e motocicleta. Os habitantes de Gerais Velho costumam se referir a si mesmos como o Povo aqui do Gerais ou o Povo do Gerais.

De acordo com um levantamento feito em 65 casas durante janeiro e fevereiro de 2013, havia 293 pessoas residindo na comunidade de Gerais Velho. Não foram encontrados moradores em seis habitações nas visitas realizadas pela assistente de pesquisa, embora houvesse informação de membros da comunidade de que pessoas residiam nas referidas casas. Em cada casa foi aplicado um questionário para o morador que se encontrava no momento da visita da assistente de pesquisa. Se houvesse mais de uma pessoa na casa, o critério de escolha era selecionar o indivíduo que possuísse papel de mais responsabilidade no grupo doméstico, segundo a concepção dos próprios moradore. Desta forma, a amostra foi composta por 43 mulheres e 22 homens.

Mesmo com um acentuado número de mulheres entre os entrevistados, devido ao fato de elas terem sido mais encontradas em casa na ocasião da aplicação do questionário, acredito que a amostra seja representativa da totalidade da comunidade para as questões levantadas. Nestes termos, podemos inferir que a população de Gerais Velho é composta majoritariamente por negros, pequenos agricultores e católicos.

As atividades rurais ocupam um lugar central na vida dos habitantes de Gerais Velho. Nas palavras dos sujeitos pesquisados, eles mexem com roça. Esta afirmação designa a dimensão do trabalho presente no cotidiano destes interlocutores. A noção de mexer opera como um equivalente do verbo trabalhar, entretanto também traduz a ideia mais ampla de lidar com algo. Já roça remete à agência de pessoas sob a terra, plantas e animais para a produção de alimentos. Como atividade produtiva, o trabalho na roça (derrubar mato, preparar a terra, plantar, colher e, em certos casos, transformar o que foi colhido, como no caso da produção de farinha de mandioca; mas também a criação de animais como vacas, porcos e galinhas) mobiliza grupo doméstico e vizinhança, produzindo e atualizando relações de afeto e consideração. Mesmo os que se declaram aposentados, afirmam ter trabalhado na roça durante a maior parte da sua vida. Outros trabalhos periódicos, sazonais ou eventuais (carvoaria, construção civil em grandes cidades etc.) se alternam e complementam as atividades rurais.

A maioria da amostra populacional da comunidade se reconhece como negra $(87,7 \%)$ e parda $(7,7 \%)$. Apesar de os processos sociais, históricos e 
culturais que levaram a uma invisibilização da presença negra no norte de Minas Gerais (Costa, 2005), a crescente mobilização política de movimentos sociais de afrodescendentes tem contribuído para a mudança deste cenário. A identificação da maioria dos entrevistados como negros é elemento fundamental para se estabelecer a relação com o reconhecimento como remanescentes de quilombos, questão que abordaremos adiante.

No levantamento feito nas residências, se verificou que o pertencimento religioso católico $(89,2 \%)$ e evangélico $(10,8 \%)$ são os únicos assumidos em Gerais Velho. Na localidade existem uma Igreja católica e um templo evangélico. Na comunidade, há um tipo de evento religioso realizado em ciclos periódicos: as festas. Estas costumam estar vinculadas a um calendário religioso católico (Nossa Senhora Aparecida, Bom Jesus, Santos Reis), mobilizando: escolhas de reis e rainhas, também chamados festeiros, responsáveis por rituais de comensalidade, em que comida e bebida são oferecidas aos membros da comunidade; cortejos e procissões que conduzem os festeiros pela comunidade; performances a cavalo, denominadas cavalhadas, em torno da igreja e da casa dos festeiros; grupos de folias homenageando Santos Reis ou Bom Jesus, personificados em bandeiras que circulam por residências.

No que diz respeito à escolarização, a maioria dos entrevistados da amostra $(73,8 \%)$ afirmou saber ler e escrever. Embora 26,8\% tenham afirmado não saber ler e escrever, apenas $12,3 \%$ informaram não ter frequentado a escola. Deduzo que o lapso entre estes dois dados indica que algumas pessoas, mesmo tendo ingressado no Ensino Fundamental, não adquiriram condições para se alfabetizar. Não tenho evidências para explicar tal processo, apenas noto que há um contingente significativo que ingressou no Ensino Fundamental, mas não o concluiu. As conversas com os moradores informam que somente a partir do fim dos anos 1970 foi construída uma escola de Ensino Fundamental, até o quarto ano primário, chamada Escola Municipal Vitalina Pereira da Cruz. Antes desse período, o acesso à escola só era possível com o deslocamento para comunidades vizinhas (Malhada Bonita ou Engenho) ou para a área urbana de Ubaí. Pessoas na faixa dos 50 anos afirmam que, na época de sua infância, seus pais pouco os estimulavam a estudar, privilegiando o "trabalho na roça".

Não há posto de saúde, mas a comunidade conta com um agente de saúde que é uma moradora local. De acordo com o relato desta agente, há uma alta incidência de doença de chagas na comunidade. Por isso, Gerais Velho foi objeto de uma política pública federal, operacionalizada pela Funasa, para a erradicação do barbeiro, inseto hospedeiro do transmissor da doença. Tal projeto implicou a construção de várias casas na comunidade substituindo antigas habitações de adobe e de pau-a-pique. Os próprios moradores da comunidade trabalharam na construção das 
casas. A agente de saúde que atende ao povoado faz visitas mensais verificando a saúde dos habitantes, oferecendo informações básicas, levantando dados para a Secretaria de Saúde municipal e levando demandas, especialmente de remédios, ao serviço médico do município.

Situada numa região do Cerrado Mineiro, uma parte considerável da vegetação nativa local deu lugar às áreas nas quais se pratica agricultura, principal atividade econômica da comunidade. A produção concentra-se no cultivo de feijão, milho, mandioca e à criação de animais como gado leiteiro e de corte, suínos e aves. A produção é feita em pequena escala e atende majoritariamente à subsistência das famílias, com o excedente sendo destinado à venda para a Conab, que repassa o alimento para os estoques que proveem merenda para as escolas municipais, inclusive a localizada na comunidade.

\section{Temporalidades e lugares da roça}

Tal como afirmado anteriormente, a categoria roça é estruturante do sentimento de pertencimento territorial do Povo do Gerais. O trabalho na roça articula-se aos dois ciclos da natureza no norte mineiro: o tempo das águas e o tempo da seca, ou simplesmente, as águas e a seca. O tempo das águas oscila mais ou menos entre outubro e março, correspondendo ao período em que as chuvas são mais frequentes e intensas. Nesta época, sobe o nível das águas do São Francisco e de seus afluentes. Com a cheia dos rios, a água transborda e forma lagoas que se transformam em criatórios naturais de peixes. Além disso, o incremento pluviométrico também aumenta o volume de água em córregos e riachos que quase desaparecem no período da seca. As áreas alagadiças que se localizam nas margens de rios, córregos, veredas ou de qualquer curso d'agua são chamadas de vazante e se constituem em terrenos férteis para a agricultura no período da seca, de abril a setembro.

Deste modo, a organização do calendário anual de trabalho conecta-se a esta temporalidade. As águas e a seca ditam o ritmo do trabalho na roça, e conforme um destes tempos se estende ou se intensifica se reorganizam as atividades laborais. Em Gerais Velho se pratica a agricultura de vazante, isto é, a atividade da roça é realizada em áreas alagadiças que surgem no tempo das águas. Na comunidade também se pratica agricultura em áreas não alagadiças. As áreas no entorno das casas servem geralmente à criação de animais ou ao plantio de hortas. As áreas de uso comum são as vazantes de um córrego da localidade que passa a maior parte do ano seco.

Trabalhar na roça é atividade considerada de muita dureza devido ao desgaste físico demandado pelo seu exercício. Por isso, o trabalho na roça não deve ser levado ao extremo do esforço físico, de modo a garantir que sempre se possa estar em condições de trabalhar. As grandes 
empreitadas, principalmente nas épocas de colheita ou de preparo para o plantio, são sempre feitas com a ajuda do grupo doméstico, parentes, compadres e vizinhos, os quais, reciprocamente, têm devolvido o favor nos momentos em que são é chamados a cooperar.

A noção de roça é construída em oposição a um "outro" no processo de elaboração do seu lugar nas práticas de sentido dos meus interlocutores. Um destes "outros" é o mato. A roça emerge onde o mato é desfeito. Os primeiros moradores de Gerais Velho plantavam pequenas lavouras sazonais, chamadas por alguns de roças de toco, em terras de matas derrubadas. Mesmo assim, o mato, nessa época, mantinha uma relação de continuidade com a roça, constituindo-se em espaço de caça de animais (veados, caititus, mocós etc.), de coleta de frutos (cagaita, araticum, pequi, mangaba, manga, laranja etc.) e mel, e de extração de "remédios do mato" (ervas variadas que são usadas, sob a forma de infusões e cremes, em práticas curativas). Com o crescimento da comunidade, progressivamente ocorreu uma redução da área de mata e, por conta disso, a quase extinção de algumas dessas práticas, especialmente as de caça, proibida pelo Ibama.

A busca por trabalho em outras localidades é um fenômeno presente na comunidade, seja em caráter temporário ou mesmo definitivo. Este deslocamento associado ao trabalho ocorre, principalmente, entre os jovens. Procurando melhor remuneração, muitos trabalhadores são agenciados por intermediários com contatos na cidade para trabalhar na colheita, sobretudo de café, nas regiões do Triângulo e Sul de Minas Gerais. Contudo, a maior parte dos deslocamentos tem como destino os grandes centros urbanos, especialmente São Paulo. Lá, os homens costumam ser alocados no setor da construção civil e as mulheres em empregos domésticos. A relação com os familiares na comunidade é mantida via envio de ajuda financeira para esposas e filhos ou pela inserção de parentes e amigos em circuitos de alocação de trabalho dos quais fazem parte.

As informações dos meus interlocutores dão conta de que a periferia da zona sul de São Paulo é o destino preferencial dos habitantes de Gerais Velho, pois lá se situam as suas redes de relações sociais. Tais redes são importantes na manutenção do relacionamento entre a comunidade de origem e a cidade de acolhimento. As narrativas acerca dos deslocamentos definitivos ou temporários de alguns interlocutores de seus familiares constituem um eixo de problematização importante a partir do qual o lugar da roça é construído pela oposição com a grande cidade, uma vez que a circulação de pessoas e coisas (bens, alimentos etc.) entre os dois espaços sociais são constantes.

A combinação de um controle sobre o tempo com uma sociabilidade não submissa a um trabalho heterônomo remete a outra dimensão da roça 
como espaço e modo vida que - não obstante a consciência dos meus interlocutores sobre o caráter duro do trabalho rural, bem como dos seus limites, em termos de acesso a determinados bens materiais - revela um modelo de reprodução social comum a muitas coletividades camponesas, mas também explicita um traço importante do modo local de elaborar um sentimento de pertencimento territorial.

As características da vida social local evidenciam que o trabalho heterônomo é tido como um dos eixos que contrastam com a vida na roça, como uma experiência vinculada às relações de parentesco e vizinhança. Quando tais relações são transpostas para uma relação patrãoempregado, padrão de relação de trabalho na cidade, mas também em áreas rurais em atividades que são desconsideradas como da roça, como cortar lenha para carvoeiras ou mesmo trabalhar diretamente na produção do carvão, podemos encontrar outro plano de problematização nativa do lugar conceitual da roça. Mexer com a roça, por meio de redes de relações de sociabilidade e de reciprocidade entre familiares e vizinhos, se constitui uma forma de trabalho autodeterminado, em contraste às modalidades modeladas pela relação patrão-empregado.

O reconhecimento de relativa autonomia laboral não impede que a associação entre trabalho e sofrimento seja muito recorrente, sobretudo nas narrativas sobre o passado. A imagem da escravidão é evocada frequentemente em relatos referentes à trajetória pessoal não só para fazer referência à descendência de pessoas escravizadas, mas, sobretudo, para situar um passado associado a um trabalho sofrido para sustentar a si próprio e aos filhos.

A memória de Seu Laro traz à tona a diversidade de atividades que já exerceu, quando solicitado a falar sobre suas experiências de trabalho: quebrar pedras para construção de cercas, corte de lenha com machado e demais trabalhos para carvoeiras. Durante nossas conversas confessoume que já trabalhou no munícipio vizinho, cortando árvores extremamente grossas na propriedade de um falecido fazendeiro. Afirma ter ficado várias vezes trabalhando por um mês inteiro com outros colegas em situação de isolamento na referida propriedade. Apenas quando encerrados 30 dias os agenciadores retornavam para reconduzilos aos seus lares. Durante este tempo, a comida muitas vezes se restringia a arroz com farinha. No retorno, voltavam no alto de carretas carregadas com carvão. Eis a escravidão de que fala Seu Laro.

Pouco sensíveis a estas narrativas, os agenciadores de trabalhadores para as carvoeiras costumam acusar os moradores de Gerais Velho de indisposição e resiliência ao trabalho. Tal acusação é conectada à outra dimensão da caracterização da comunidade: a sua identificação como um lugar de negros. O sustento ideológico das relações de poder na região 
engendra a partir desse eixo a acusação moral dos negros como "preguiçosos".

\section{Pertencimento e visibilidade}

O sentimento de pertencimento étnico-racial do Povo do Gerais ganha contornos próprios, se comparado com a comunidade de Ribanceira, situada no município vizinho de São Romão, na qual realizei a pesquisa para minha tese de doutorado. Gerais Velho já havia obtido uma certidão de autorreconhecimento como remanescente de quilombo, da Fundação Cultural Palmares. O contato com moradores de Gerais Velho se deu a partir de relações de parentesco entretidas por alguns de seus membros com habitantes da Ribanceira. Interlocutores da Ribanceira costumavam afirmar "lá é um lugar de descendentes de quilombolas". Tal expressão colocava em relevância dois aspectos para eles: a marcante presença de população negra e o reconhecimento oficial da identidade quilombola do Povo do Gerais. Fato que atestei posteriormente, ao notar que além da certificação da Fundação Palmares, havia um processo em tramitação no Incra para a titulação das terras.

Na minha primeira visita à comunidade, notei que meus companheiros da Ribanceira eram conhecidos apenas por uma família da comunidade, em que uma ex-moradora da Ribanceira havia contraído matrimônio com um rapaz de Gerais Velho. Em contatos com outros moradores do distrito, eles eram interpelados sobre de onde vinham. Ao se identificarem como moradores da Ribanceira, logo eram saudados com expressões como: "Ah, então são do Gerais", "é tudo do Gerais". Tal associação dizia respeito ao reconhecimento das conexões de parentesco, seja por meio de filiação unilinear entre determinadas pessoas ou alianças matrimoniais entre moradores das duas comunidades. Entretanto, a cor da pele também era evocada nas conexões. Em uma das mútuas apresentações entre eles ouvi: "logo vi, pretinho desse jeito (...) e se é da Ribanceira, também é do Gerais". Ainda que esta caracterização da negritude não tenha sido objeto de desacordo entre meus amigos da Ribanceira naquele momento, em muitos outros contextos a sua identificação como negros é problemática, devido à forma como a imagem social do negro foi elaborada historicamente no norte mineiro.

A presença de populações afrodescendentes ganha destaque em pesquisas historiográficas sobre a escravidão no norte de Minas Gerais. Sob uma perspectiva demográfica, cabe ressaltar que a população escrava, já em meados do século XIX, representava menos de um quinto da população de Montes Claros e dos distritos da Comarca do São Francisco, conforme Botelho (2000). Entretanto, a decrescente presença da população cativa, ao longo do século XIX no norte de Minas Gerais, não minimizou a sua importância na vida social regional. Em uma investigação sobre as 
relações entre violência, escravidão e justiça no norte de Minas Gerais, entre os anos de 1830 e 1888, Alysson Jesus (2007) demonstrou a existência de alguns aspectos horizontais no convívio entre escravos, libertos e homens livres, deixando marcas na identidade dos habitantes da região. Nas palavras do autor:

Trata-se de um mundo que tornou escravos, libertos e homens livres em parceiros no crime e companheiros no lazer. Um mundo que aproximou, em muitos casos, os senhores de seus próprios cativos, visto que foi necessária a participação dos primeiros, por exemplo, no trato com a roça, papel sempre visto como função exclusiva dos segundos. Assim, o braço do homem livre se confundiu com o do cativo, permitindo a conformação do sistema escravista a partir de uma "feição desorganizada" (...). Nesse sentido, aparentemente algumas situações, modelos ou regras foram subvertidas, moldando um ambiente mais heterogêneo e imprevisível, ao invés de um mundo coerente, normalmente esperado pelas relações estabelecidas na ordem escravista. É a partir daí que, acreditamos, suas identidades vão sendo moldadas. (JESUS, 2007, p. 79)

De forma complementar, ao colocarmos em diálogo tanto a literatura de viajantes como da etnografia de outras localidades mineiras ou do Vale do São Francisco (SILVA, 1961; COSTA, 1999; OLIVEIRA, 2005), bem como os relatos obtidos no trabalho de campo, podemos notar que há um jogo de visibilização-invisibilização da presença de populações não brancas cuja variação está articulada à posição de enunciação das fontes de informação. A questão racial no Brasil, desde o século XIX, com os pioneiros "estudos de negros", remete ao enfrentamento de uma temática candente até os dias atuais: aquela que envolve a identidade (SCHWARCZ, 1999, p. 268). O tema do pertencimento identitário é um dos principais eixos de conflitos e embates políticos que mobilizam setores importantes não só da sociedade brasileira, como do mundo globalizado.

O conjunto de estudos produzidos pelas ciências sociais no Brasil, “a partir de pesquisas de base mais demográficas que têm sublinhado, nos últimos anos, as marcas da desigualdade, e das etnografias e estudos de caso, que revelam os usos da identidade e as releituras das manifestações culturais de base étnica" (idem), tem permitido avançar no debate sobre as formas de hierarquização social e as distintas modalidades de reivindicações de direitos, em uma sociedade como a brasileira, que constrói em ritmos e processos diferenciados suas conquistas democráticas.

Conforme João Batista de Almeida Costa (2005), as populações afrodescendentes tomadas como comunidades negras rurais, e atualmente categorizadas política e juridicamente como quilombolas, têm ganhado visibilidade pública apenas nas últimas duas décadas na região 
norte de Minas Gerais. Tal fenômeno, também ocorrido em escala nacional, tem como processo catalisador as prerrogativas geradas a partir do marco histórico estabelecido pelo artigo 68, dos Atos das Disposições Transitórias da Constituição Federal de 1988, que reconhece o direito à propriedade às Comunidades Remanescentes de Quilombos (ARRUTI, 1997, 2006; BRANDÃO; DALT; GOUVEIA, 2010). A invisibilidade repousaria na

estratégia interna a cada grupo, construída historicamente por seus membros, para garantirem a vivência do grupo e para se inserirem, sem diferenciação, nas relações vividas no contexto social e político em que se encontravam, e, de estratégia externa, como negação de suas existências na história local, regional e nacional. (COSTA, 2005, p. 2)

\section{Atores religiosos e mobilização étnica}

Em Gerais Velho, a análise da emergência de uma identidade comunitária afrodescendente passa pela compreensão da ação de pessoas ligadas ao segmento católico local. A igreja local, situada ao lado da escola, é um dos núcleos a partir dos quais a comunidade se organiza como tal (o outro diz respeito às duas associações comunitárias). Dados apresentados anteriormente atestaram a presença majoritária de católicos na comunidade. A igreja é o lócus de várias atividades religiosas: encontro de grupos de oração, novenas, espaço de festas religiosas locais, que são motivos, inclusive, de visitas passageiras dos familiares que se encontram em São Paulo. Contudo, outras atividades também acontecem no seu interior e no pátio externo: pesagem de crianças pela Pastoral da Criança (interior da igreja), atividades culturais, como danças de batuque, capoeira, leilões comunitários e até festas de forró (área externa).

As principais festas religiosas que mobilizam a comunidade são a de Bom Jesus, no início de agosto, e de Santos Reis, no início de janeiro. Ambas são estruturadas a partir do giro de ternos de folias. As folias conformam-se, de modo geral, em três momentos rituais. O primeiro diz respeito à saída da folia, que tem início com o levantamento do mastro com a bandeira do santo celebrado. A bandeira é entregue pelo festeiro, em sua casa, aos foliões para que sejam iniciados os giros. Este momento ritual implica uma preparação, por vezes, de semanas ou até meses de antecedência. Esta preparação envolve os mesmos elementos das festas de reinado citadas no item anterior: a mobilização de uma rede de ajuda para custear e organizar a festa, por meio de leilões, doações e prestações de serviços, gerando dádivas e saldando dívidas, materiais e simbólicas, e, assim, alimentando um fluxo de produção e extensão de influência pessoal. Esse momento ritual se dá com a chegada dos foliões à casa do 
festeiro. Lá são feitas rezas por todos, em frente à lapinha $a^{5}$ montada para o evento, para solicitar proteção ao giro dos foliões, daqueles que os acompanham e daqueles que serão visitados. Nesse momento é servida a refeição, almoço ou janta, aos foliões e convidados. Os foliões tocam e cantam músicas, dançam a sussab, e partem para realizar o giro nas casas da redondeza.

O segundo momento ritual é, propriamente, o do giro da folia. $\mathrm{O}$ giro consiste na sucessão de visitas e pousos nas casas, sítios ou fazendas, intercalados pelo deslocamento, curto ou longo, no trajeto entre cada moradia. As visitas quase sempre são pedidas por determinados moradores. Eventualmente, os foliões fazem visita às casas não programadas pelo pedido de seus residentes. Segundo meus interlocutores, os foliões "não vão às casas de povo de outra religião". Isto é, a folia evita a visita aos evangélicos, pois estes, mesmo sendo cristãos, não compartilham dos princípios que fundamentam este tipo de celebração festiva. Aos que recebem a visita é obrigatório o oferecimento de algo para os foliões e seus acompanhantes comerem ou beberem. As ofertas mais simples incluem biscoitos, bolos, café e cachaça. Em troca, os foliões trazem bênçãos por meio da bandeira que personifica o santo homenageado, e que o anfitrião conduz por todos os cômodos da casa, e dos cânticos que executam durante a visita. Tais cânticos são ordenados pela chegada, pela estada e pela despedida da casa. Há o momento de oferecer os biscoitos e café aos foliões, entre a pausa da cantoria e o momento de dançar a sussa. Este último só é realizado quando a bandeira do santo é deixada em um quarto, sem a presença dos foliões. Então, no espaço em que a folia e seus acompanhantes são recepcionados é dado início à dança coletiva da sussa, em que qualquer participante pode dançar, requebrando e gingando, no meio de uma roda composta pelos foliões, que tocam músicas ritmadas e intensas, e demais participantes. Nesse momento, os foliões também estão livres para consumir a pinga ou qualquer outra bebida alcoólica ofertada. Os pousos correspondem às visitas mais longas, em que os residentes oferecem almoço ou janta e local para descanso aos foliões. Nessas moradas também são executados os mesmos ritos das demais visitas.

O último momento ritual é o da entrega da folia, na casa do festeiro. Esta fase é também composta de uma sequência de atividades ritualizadas. Elas compreendem a chegada dos foliões à casa do festeiro, a reza,

\footnotetext{
${ }^{5}$ Santuário montado sob a forma de um pequeno altar com um presépio e pequenas imagens em porta-retratos de Jesus Cristo, Nossa Senhora Aparecida ou do Rosário, e/ou do santo homenageado com a folia. A "lapinha" é sempre montada na sala ou peça de circulação de pessoas na casa do "festeiro". Em frente a ela são feitas as rezas e as apresentações dos foliões. ${ }^{6}$ Dança popular, executada nas ocasiões de folia, que em outras regiões de Minas Gerais ou do Brasil também pode receber o nome de catira, lundu, curraleira (BRANDÃO, 1981; MARTINS, 1991).
} 
conduzida em ladainha por uma ou duas "rezadoras", em frente à "lapinha" e acompanhada por vários membros da comunidade ali presentes. Inclusive, a entrega da folia costuma ser o momento mais frequentado ritual. $\mathrm{O}$ festeiro oferece uma refeição, preparada em mutirão pela rede de apoio mobilizada, aos foliões e comunidade. Então é feita a entrega, propriamente dita, da folia. Os foliões entregam simbolicamente a bandeira, toalhas e instrumentos musicais ao festeiro. Após a entrega da folia, o festeiro costuma oferecer um forró ${ }^{7}$ aos foliões e à comunidade presente.

Há dois ternos de folia no povoado: um, cujo folião-guia é Seu Laro; e outro comandado por Silvano. Em 2012, acompanhei o terno de Seu Laro, que foi um dos meus principais interlocutores na comunidade. A folia começou na comunidade vizinha de Serragem, e depois concentrou seu giro nas casas de Gerais Velho. Os ternos de folia são identificados com a comunidade de onde provêm e são agentes de construção da identidade das referidas comunidades. Isto é, os ternos de folia são agentes do trabalho que produzem o sentido do pertencimento à Comunidade de Gerais Velho, ou como meus interlocutores afirmam, o pertencimento ao Povo do Gerais.

Em Gerais Velho, a reivindicação da identificação como comunidade quilombola tem sua articulação associada às atividades de duas lideranças femininas da localidade: Benedita e Justina. Ambas mexem com a Igreja, isto é, são membros atuantes da paróquia local. Benedita é casada com Pedro, irmão de Justina. São cunhadas e parceiras nas lides da igreja e na mobilização da comunidade em torno da identidade quilombola. Benedita foi minha principal anfitriã durante a minha pesquisa de campo. Fiquei hospedado na sua casa em duas ocasiões; em outra, fiquei alojado na casa ao lado da igreja, que geralmente serve para acolher o padre que reza uma missa a cada mês, cuja chave fica na sua posse.

Benedita me apresentou Justina como coordenadora das atividades pelo reconhecimento de Gerais Velho como comunidade quilombola. O interesse no referido reconhecimento surgiu no momento em que Justina estava, como liderança comunitária, cadastrando a comunidade no programa "Leite para todos". A partir do contato com a assistente social da Prefeitura, Justina começou a mobilizar a comunidade em relação aos inúmeros procedimentos estatais ainda não concluídos para o reconhecimento da comunidade como quilombola.

Durante este processo, a assistente social da Prefeitura teria entrado em contato com a Fundação Palmares que enviou um representante para fazer reuniões na comunidade. Após as visitas e reuniões do representante da entidade, foi conferido à comunidade uma certidão de autorreconhecimento como quilombola, mas ainda sem a demarcação

${ }^{7} \mathrm{O}$ forró em questão é um baile realizado na área externa da casa do festeiro ou da igreja local. 
territorial, procedimento a cargo do Incra. No que diz respeito à pesquisa amostral do meu projeto de pesquisa, a maioria dos sujeitos entrevistados que se considera negro, também se considera quilombola (96,5\%). Da amostra, apenas dois indivíduos brancos e um pardo afirmaram não se considerarem quilombola. Os demais pardos também se consideram quilombola. A categoria Outra foi preferida por apenas um indivíduo, que afirmou se considerar "moreno", mas que também se pensa como quilombola.

A atividade de reconhecimento de comunidades remanescentes de quilombos deriva do disposto no artigo 68 da Constituição Federal. A demanda social das comunidades associadas ao dispositivo jurídico constitucional produziu um longo debate no campo da antropologia brasileira, uma vez que o trabalho de elaboração de laudo antropológico é um dos mecanismos do complexo sistema estatal de reconhecimento. $\mathrm{O}$ espaço deste artigo não tem como reconstituir o debate que conduziu as práticas nativas de autoatribuição para o centro da análise antropológica destes processos nem as controvérsias no plano político que o interesse sobre os territórios quilombolas despertam. Para este propósito, os trabalhos de Arruti $(1997,2006)$ e Mello (2012) são extremamente valiosos. De qualquer maneira, trabalhamos com uma perspectiva relacional que não reduz as formas de pertencimento territorial aos processos de instrumentalização política para o reconhecimento jurídico da identidade quilombola. Antes estamos atentos aos aspectos que estão aquém e além destas reivindicações, como o trabalho na roça e a religiosidade, mesmo que estes sejam agenciados pelos atores locais nas suas reivindicações identitárias perante o Estado.

O reconhecimento oficial pela Fundação Palmares criou condições para a participação em programas do governo federal orientados para comunidades quilombolas. A alocação de recursos destes programas é objeto de disputas internas à comunidade. Na época da realização do trabalho de campo, Gerais Velho contava com duas associações comunitárias, e havia uma terceira, em vias de oficialização. A mais antiga é a Associação dos Pequenos Produtores Rurais de Gerais Velho, criada em meados dos anos 1980. O descontentamento de parte dos antigos associados com a gestão de recursos provindos de verbas públicas, mesmo antes do reconhecimento como comunidade quilombola, fez com que nos anos 1990 uma dissidência da referida associação criasse a Associação dos Pequenos Produtores Rurais do Novo Gerais, cuja presidente, à época em que realizei minha pesquisa, era Benedita. A associação mais antiga mantinha um maior número de associados (63,1\%). Já a do Novo Gerais possuía 23,1\%, enquanto 13,8\% afirmavam não estar filiados a nenhuma associação. Tais percentuais levam em conta a razoabilidade de se aceitar que cada indivíduo da amostra que 
respondeu ao questionário pudesse estender a sua posição para o restante da unidade doméstica.

Quando da realização do trabalho de campo, havia uma terceira associação em vias de criação: Associação Quilombola Palmares do Bom Jesus. Em visita recente à comunidade, obtive a informação de que ela foi criada e substituiu a Associação dos Pequenos Produtores Rurais do Novo Gerais, cujos associados migraram para a nova agremiação. A nova associação tinha por objetivo representar os interesses de seus membros como grupo étnico racial remanescente das comunidades de quilombos, tal como expõe o seu estatuto social. Dentre os referidos interesses estariam, conforme relatos de seus membros, a gestão de recursos oriundos de políticas públicas específicas para tais comunidades, uma vez que apenas a Associação dos Pequenos Produtores de Gerais Velho recebia esses aportes. A primeira presidente da Associação Palmares do Bom Jesus foi Justina. A sua oficialização jurídica ainda dependia, à época da pesquisa de campo, do registro em cartório da ata da reunião que criou a associação, bem como o seu envio à Fundação Palmares. Tais requisitos foram cumpridos posteriormente. $\mathrm{O}$ nome da nova entidade remete diretamente à devoção de Bom Jesus, não por acaso a figura sacra a quem é dedicada uma das principais festividades religiosas anuais na comunidade.

A existência de duas associações evidencia disputas e conflitos em torno da gestão de recursos financeiros de políticas setoriais, embora não seja evocada como princípio disjuntivo da comunidade, nas narrativas dos meus interlocutores. Pessoas filiadas a distintas associações fazem questão de ressaltar em seus relatos que elas são "tudo Gerais", "Gerais é um só". Se articularmos a análise dos diferentes discursos, proferidos em diversos contextos de enunciação, compreenderemos que as relações de sociabilidade em cenários distintos como o trabalho, bares, jogos de futebol ou as festas religiosas costumam ser fonte de referência do sentimento de pertencimento ao lugar mais do que as divisões políticas internas à comunidade.

Os conflitos de visões são relevantes, ainda que minimizados retoricamente pelos meus interlocutores. Há posições, sobretudo de pessoas ligadas à Associação Palmares do Bom Jesus, que afirmam não fazer sentido pessoas receberem recursos e outras não na comunidade. Afinal, todos teriam "cabelo duro. Todos são negros". Outras pessoas não consideram interessante o reconhecimento como quilombola, principalmente no que diz respeito aos efeitos que isso pode ter em relação à posse sobre o território. Em uma conversa com Dona Benedita, eu comento sobre os problemas políticos de outros grupos indígenas e quilombolas que têm seus territórios ameaçados por grandes empreendimentos estatais ou privados, fazendeiros praticantes de 
monocultura e grileiros. Minha interlocutora afirma compreender o problema e me conta que, no passado, sua mãe vendeu parte da sua terra, e que isto hoje não é possível porque em Gerais Velho haveria "pouca terra para muita gente". Contudo, ela faz a ressalva de que algumas poucas pessoas da comunidade com mais recursos financeiros não teriam interesse na reivindicação da identidade quilombola, pois se a terra se tornasse de posse coletiva e, portanto, invendável, elas temeriam "perder com isso".

Em outra situação, Dona Benedita me relata que durante os anos em que morou em São Paulo trabalhou como voluntária em projetos sociais de uma paróquia da localidade em que residia. Nesta época teria conhecido muitas pessoas, sobretudo oriundas do nordeste do país, que se encontravam em situação de vulnerabilidade, sem emprego, nem renda. Perguntou a muitas delas porque não voltavam para os seus locais de origem. As pessoas, a maioria de origem rural, lhe respondiam que não possuíam mais "terra", que esta havia sido vendida, seja pelos próprios migrantes ou pelos familiares. Benedita se sentia entristecida com esta situação e lembrava que ela e os seus conhecidos do Gerais, mesmo morando em São Paulo, ainda tinham a sua terrinha para voltar um dia. Ao mesmo tempo, sabia que as necessidades materiais faziam com que muitos vendessem suas terras para pagar dívidas ou para buscar melhores oportunidades de vida em outros locais. Ciente disto, ela afirma que a certificação pelo Incra, e não apenas pela Fundação Palmares, transformaria o território de Gerais Velho em propriedade de uso coletivo, que não poderia se vendida e, portanto, resguardaria a posse da terra para as gerações futuras do Povo do Gerais.

\section{Comentários finais}

Diante do exposto, podemos compreender que a construção do sentido de pertencimento dos sujeitos da população afrodescendente de Gerais Velho se entrelaça com a relação entre a atividade laboral e o modo de vida característico da roça, a religiosidade e a sociabilidade comunitária, a filiação às associações comunitárias e a identidade quilombola e sua correlação com o território. Embora se faça presente, a dimensão da memória não foi enfocada neste artigo.

No que diz respeito aos aspectos territoriais, a situação estudada guarda semelhança com a reflexão de Ilka Boaventura Leite quanto ao reconhecimento jurídico de remanescentes de quilombo:

A terra, portanto, não é o que identifica os sujeitos do direito e sim a sua condição de membros de um grupo. A terra, evidentemente, é crucial para a continuidade do grupo, do destino dado ao modo coletivo de vida destas populações, mas não é o elemento de identificação principal. (...). 
A terra é o que propicia condições de permanência, de continuidade das referências simbólicas importantes à consolidação do imaginário coletivo, e os grupos chegam por vezes a projetar nela sua existência, mas não tem com ela uma dependência exclusiva. (...)

Este enfoque põe em destaque mais do que a cor da pele: a capacidade de auto-organização e o poder de autogestão dos grupos para identificar e decidir quem é e quem não é um membro de sua comunidade. (LEITE, 1999, p. 136-137)

Em Gerais Velho, a categoria roça não se desconecta da imagem da terra. Nesse contexto, mexer (trabalhar) também é movimentar. Um movimento que se faz na e com a terra. Ao mesmo tempo, mexer com a roça não deixa de ser ação de pessoas que modifica, põe em movimento a terra, o mato, os animais, as plantas e a si próprio.

Se a roça identifica o Povo do Gerais, a comunidade também se consolida como um referencial importante mesmo para aqueles que se deslocam para morar por muitos anos em São Paulo. $\mathrm{O}$ experimento de liberdade construído cotidianamente pelos moradores de Gerais Velho diz respeito a poucas pessoas, é verdade. Entretanto, tal experiência se replica nas festas vinculadas ao calendário religioso católico, quando trazem de volta à comunidade aqueles que de lá se afastaram em busca de melhores oportunidades de vida.

$\mathrm{O}$ autorreconhecimento como negros e, posteriormente, como quilombolas faz parte deste exercício de luta por autonomia, ainda que esta venha a ser relativa no contraponto com a vida que não deixou de ser dura, mesmo quando comparada ao passado. A situação de Gerais Velho suscita reflexão em outras comunidades como a Ribanceira, comunidade negra rural localizada no município de São Romão, que pesquisei no período de doutorado. Havia uma curiosidade crescente pela passagem à condição quilombola, seu passado ligado à escravidão e às conexões de parentesco ainda pouco explicitado para muitos moradores da Ribanceira, bem como a uma percepção de mais autodeterminação do Povo do Gerais.

A ideia nativa de pertencimento parece associada a uma ideia de movimento em contraste com a de fixação, ainda que a terra, na qual se produz e vive, seja um referencial importante. Tal movimento se constitui por meio da própria experiência de transitar: da casa para o trabalho, do trabalho para o bar, do Gerais para as comunidades vizinhas ou para São Paulo, de casa em casa nos giros de folia, da percepção como negros para a identidade quilombola, da filiação a diferentes associações ao sentimento de que as divergências são uma face do pertencimento a uma só comunidade. Nesses movimentos é que são produzidos e atualizados os elos sociais que tecem o sentido de pertencimento dos meus interlocutores. A apreensão destes movimentos carrega um sentido de liberdade e autonomia, mesmo que relativo, para aqueles que afirmam 
pertencer ao Povo do Gerais. O Gerais se faz e se carrega nas itinerâncias do seu Povo.

\section{Referências bibliográficas}

ARRUTI, José Maurício Andion. A emergência dos remanescentes: notas para o diálogo entre indígenas e quilombolas. Mana, v. 3, n. 2, 1997, p. 738.

ARRUTI, José Maurício Andion. Mocambo: Antropologia e História do processo de formação quilombola. Bauru: Edusc, 2006.

BOTELHO, Tarcísio Rodrigues. Demografia e Família Escrava em Montes Claros no Século XIX. In: OLIVEIRA, Marcos Fábio Martins et al. Formação Social e Econômica do Norte de Minas. Montes Claros: Editora Unimontes, 2000.

BRANDÃO, André; DALT, Salete; GOUVEIA, Victor Hugo. Comunidades Quilombolas no Brasil: características socioeconômicas, processos de etnogênese e políticas sociais. Niterói: Editora UFF, 2010.

BRANDÃO, Carlos Rodrigues. Sacerdotes da Viola. Petrópolis, RJ: Vozes, 1981.

COSTA, João Batista de Almeida. A cultura sertaneja: conjugação de lógicas diferenciadas. In: SANTOS, G. R. Trabalho, Cultura e Sociedade no Norte/Nordeste de Minas: considerações a partir das ciências sociais. Montes Claros: Best Comunicação e Marketing, 1997.

COSTA, João Batista de Almeida. Do Tempo de Fartura dos Crioulos ao Tempo de Penúria dos Morenos: a identidade através de um rito em Brejo dos Crioulos. Brasília: DAN/UnB, 1999.

COSTA, João Batista de Almeida. A reescrita da história, a valorização do negro e a atualização das relações ancestrais no Norte de Minas. Revista Verde Grande, v. 1, n. 2, p. 12-52, 2005.

BURTON, Richard Francis, Sir. Viagem de canoa de Sabará ao Oceano Atlântico. Belo Horizonte/Itatiaia/São Paulo: Edusp, 1977.

GOMES, Flávio dos Santos. Histórias de Quilombolas. São Paulo: Cia das Letras, 2006.

GOMES, Flávio dos Santos. Mocambos e Quilombos: uma história do campesinato negro no Brasil. São Paulo: Claro Enigma, 2015.

JESUS, Alysson Luiz Freitas de. No Sertão das Minas: Escravidão, violência e liberdade (1830-1888). São Paulo: Annablume/Belo Horizonte: Fapemig, 2007. 
LEITE, Ilka Boaventura. Quilombos e quilombolas: cidadania ou folclorização? Horizontes Antropológicos, v. 5, n. 10, p. 123-150, 1999.

LIMA, Nísia Trindade. Um sertão chamado Brasil. Rio de Janeiro: Revan/IUPERJ, 1999.

MARTINS, Saul. Folclore em Minas Gerais. Belo Horizonte: UFMG, 1991.

MELLO, Marcelo Moura. Reminiscências dos Quilombos: territórios da memória em uma comunidade negra rural. São Paulo: Terceiro Nome/FAPESP, 2012.

NEVES, Zanoni. Navegantes da Integração: os remeiros do rio São Francisco. Belo Horizonte: Editora UFMG, 1998.

OLIVEIRA, Cláudia Luz de. Vazanteiros do Rio São Francisco: um estudo sobre populações tradicionais e territorialidade no Norte de Minas Gerais. 2005. 134 f. Dissertação (Mestrado em Sociologia) - Faculdade de Filosofia e Ciências Humanas, Universidade Federal de Minas Gerais, Belo Horizonte, 2005.

PIERSON, Donald. O Homem do Vale do São Francisco. Vol. II. Rio de Janeiro: Ministério do Interior/Superintendência do Vale do São Francisco, 1972.

SCHWARCZ, Lília K. M. Questão Racial e Etnicidade. In: MICELI, Sérgio (Org.). O que ler na ciência social brasileira (1970-1995) - Antropologia. 2. ed. São Paulo: Sumaré/Brasília: CAPES, 1999.

WAGLEY, Charles (Org.). Race and Class in Rural Brazil. Nova Iorque: Columbia University Press, 1952.

BENITES, Luiz Felipe Rocha. Veredas do pertencimento ao Povo do Gerais: roça, religião e mobilização étnica em movimento. Estudos Sociedade e Agricultura, v. 27, n. 1, p. 167-184, fev. 2019.

Resumo: (Veredas do pertencimento ao Povo do Gerais: roça, religião e mobilização étnica em movimento). $\mathrm{O}$ artigo busca refletir sobre como o sentimento de pertencimento a Gerais Velho, uma comunidade negra rural no sertão mineiro, conecta terra, trabalho, religião e negritude, por meio das itinerâncias dos seus membros. Partindo de uma perspectiva etnográfica, o movimento das pessoas que fazem parte da comunidade é usado para deslocar a própria ideia de pertencimento dos quadros analíticos da fixação, tão comum entre as abordagens identitárias. Desta forma, se desenham os 
caminhos pelos quais a autonomia e a liberdade ganham sentido na vida experimentada como mobilidade pelo Povo do Gerais.

Palavras-chave: pertencimento; roça; religião; negritude; mobilidade.

Abstract: (Pathways of belonging to the People of Gerais: crop production, religion and ethnic mobilization in motion). This article intends to analyze how the sentiment of belonging to Gerais Velho, a black rural community in the backlands of Minas Gerais, enfolds land, religion and black identity through the roaming of their inhabitants. Stemming from an ethnographic perspective, it uses the movements of the Gerais Velho inhabitants to shift the idea of belonging from the analytic frames of fixation, common in the treatment of identities. Thus, it traces the pathways by which autonomy and liberty make sense to a life experienced as mobility.

Keywords: belonging; farm; religion; blackness; mobility.

Recebido em outubro de 2017. Aceito em janeiro de 2018. 